\title{
Crashworthiness Analysis of Octagonal-Inner Double Tube with different thickness under Off- Axis Oblique Load
}

\author{
Ilyas Renreng, Muh. Farid Hidayat, Fauzan Djamaluddin \\ Department of Mechanical Engineering, University of Hasanuddin, Poros Malino Km. 6, 92171 \\ Bontomarannu, Gowa, South Sulawesi \\ Indonesia
}

Received: October 17, 2020. Revised: December 7, 2020. Accepted: December 10, 2020.

Published: December 14, 2020.

\begin{abstract}
The crash tube is one of the important parts to reduce the effects of accidents. The design of crash tube only watches the frontal crash, but oblique crash might affect the passengers. Besides, Lack of oblique-loading researches in crashworthiness becomes causes to analyze crash tubes more. This paper aims to study crashworthiness performance of octagonal-inner double tubes under off-axis oblique impact load $\left(0^{\circ}, 10^{\circ}, 20^{\circ}\right.$, and $30^{\circ}$ ). The tubes have been connected with two walls, top wall as moving wall and a bottom wall as rigid wall underl different load angles. The tubes were made from Aluminum Alloy and consisted of a circular-outer tube and an octagonal-inner tube. The crashworthiness parameters of absorption of specific energy (SEA), maximum collapse force (Fmax) and efficiency of crush force (CFE) were obtained for all the structures. In order to get the value of parameters, the method of finite element analysis was used. The effects of different thickness of 1 $\mathrm{mm}, 2 \mathrm{~mm}, 3 \mathrm{~mm}$ and $4 \mathrm{~mm}$ and various oblique were studied. Based on numerical results, structures of $4 \mathrm{~mm}$ thickness were the greatest SEA of $26.39 \mathrm{~kJ} / \mathrm{kg}$ among other thickness of structures. In addition, the value of energy absorption for tubes obliquely loaded decreased for all the size of thickness structures. Finally, this structure can be considered as crash box of vehicle in future.
\end{abstract}

Keywords-Crashworthiness, Finite element analysis, Off-axis oblique load, Thickness, Double tube.

\section{INTRODUCTION}

$\mathrm{T}$

The global automotive industry is looking for component alternatives to its materials to limit energy consumption and fulfill more and more stringent environmental rules. In this case, to eliminate conventional steel parts, advanced designs and materials such as aluminum alloys are incorporated into the automotive body. However, heavy component to be reduced of the auto parts needs the reassessment or redesign of passive parts of the auto body related to safety, such as the frontal rail components. Frontal rail components, well known as thinwalled structures, are the major energy-absorbing features in frontal impact analysis. These thin-walled structures are essential to learn due to affecting the passenger's safety in cars.

Because of the reasons mentioned above, thin-walled structures have been started to be applied by researches. For instance, Manmohan Dass Goel [1] studied investigation on numerical simulation of axial impact loading behavior of single, doubled and stiffened tubes using aluminum alloy. In other study, Zhang et al. [2] researched about dynamic and static axial crush of self-locking multi-cell tubes with sheet material AA6063. In addition, Djamaluddin et al. [3] [4]used half and full aluminum foam filled circular-double tube under multiple load cases in order to optimize and validate.

Several researches have also been created on double tube. For example, I. Vimal kannan and R. Rajkumar [5] analysed deformation and absorbed energy of simple and multi-cell thin walled tubes under quasi-static crushing. Annisa Yusuf et al. [6]researched about analysis of crashworthiness of multi-cell prismatic structures by both simulation and experimental case. Ali Ahmadi Dastjerdi et al. and Djamaluddin [7] [8] investigated multi-objective optimization of different length on tubular thin walled cylindrical structures under axial impact loading for analyzing crush of the tubes. Xiong Zhang and Hui Zhang [9] used cross section of circular multi-cell columns and relevant specimens to analyze crushing behavior and energy absorption under axial loading. 
Not only the shape of thin-walled structures has been analysed so far, also the thickness of the tubes are starting to be investigated. Guangyong Sun et al. [10] evaluated analysis of crash and multi objective optimization for structures with various grade thickness of the tubes. Annisa Jusuf et al. [6] carried out analysis of crashworthiness of multi-cell prismatic structures with different inner and outer wall thickness. In addition, choices of material for thin-walled structures become widely essential to get cheaper price. Kaczyński, Gronostajski, and Polak [11] used magnesium alloy crash-boxes for crushing study to get a new mechanism of energy absorption. Other material that has been investigated more is natural composite. Eshkoor et al. [12] reported that woven natural silk/epoxy rectangular composite tubes to know failure mechanism of under axial quasi-static crushing test using trigger mechanism. Furthermore, Anghileri et al. [13] analyzed behavior of composite skin panel in numerical approaches in a water impact.

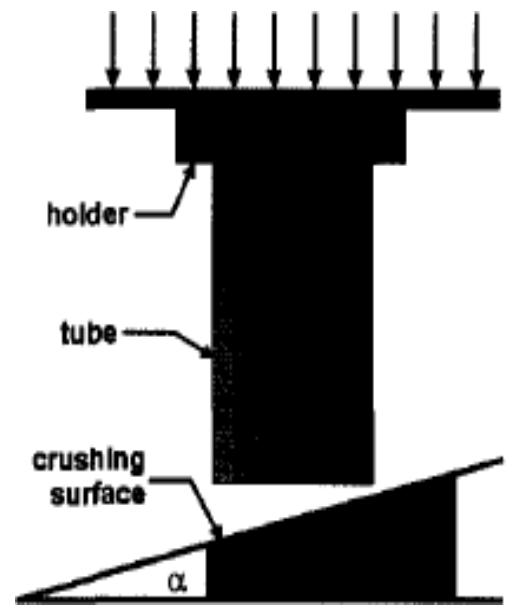

(a)
During a real crush case, an energy-absorbing system can rarely either encountered pure axial or pure bending collapse. Instead, both axial loading and moment is produced in the structure which causes oblique loading conditions. It is necessary to recognize what happens to the design during oblique loads as part bending collapse due to low energy absorbing ability may not fit crashworthiness design objectives. Figure 1 described two categories of oblique loads; angled loading and off-axis loading [14]. Limited studies have been conducted in this field until now.

Kim and Wierzbicki [15] defined two forms of oblique loading: crushing off-axis, and crushing angled. The researches got tested pultruded E-glass/polyester tubes typically consumed more energy in the angled packing, which they concluded was because of the presence of static friction in the angled crushing as opposed to the dynamic friction in the crushing off-axis. Distinguish in energy absorption was found to be highly dependent on the impact angle.

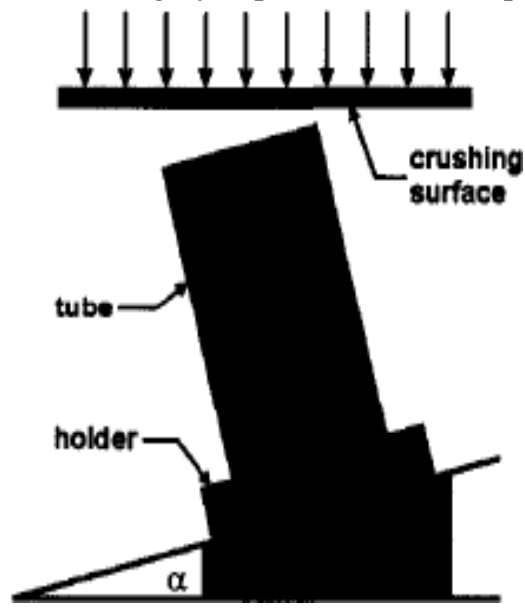

(b)

Fig. 1 Types of oblique crush (a) angled loading (b) off-axis loading [14]

Windowed tubes were studied to oblique impact crush and a new manner for the design of obliquely loaded tubes through numerical simulation researched by Jie Song [16]. Another treatment of crash box such as honeycomb filled crash box under oblique impact loading was designed by Mohammadiha, Beheshti, and Aboutalebi [17]. Oblique loading for analyzing crush and optimizing multi-objective crashworthiness using multi-cell conical tube was carried out by Xiaolin and Wangyu [18]. The combination of shape optimization under high velocity axial and transverse impact loading was conducted for thin-walled tubes by Tanlak [19].

In consequence, to know the influence of crash double tubes with octagonal-shape inner tubes, the research about crashworthiness octagonal inner double tubes under oblique loading should be studied. The various thicknesses of tubes have been recognized to see the most outstanding tubes in absorbing energy and deformation of the structures.

\section{GEOMETRY AND NUMERICAL SIMULATION DESCRIPTION}

Figure 2 shows the tubes analyzed in this study. The tube is categorized as double tube consisting of inner tube and outer tube. Shape for outer tube is circular with $90 \mathrm{~mm}$ of the diameter while shape for inner tube is octagon with the size displayed in figure 2c. Total length of all the structures is $180 \mathrm{~mm}$. The structures for both inner tube and outer tube have different thickness of $1 \mathrm{~mm} 2 \mathrm{~mm}, 3 \mathrm{~mm}$ and $4 \mathrm{~mm}$. The tubes have been connected with two plates, an upper plate for moving wall or mass plate and a lower plate as rigid floor. Meanwhile, the method of this research is off-axis oblique loading. The lower plate is beveled with angles of $0^{\circ}, 10^{\circ}, 20^{\circ}$, and $30^{\circ} .16 \mathrm{~m} / \mathrm{s}$ of moving plate is depicted and mass $16000 \mathrm{~kg}$ is impacted to the tubes until the structures were crushed for all impact simulations.

Material used for all the structures is Aluminum Alloy 6060 T4 with mechanical properties; initial yield stress $\sigma_{y}=$ $80 \mathrm{MPa}$, Young's modulus $E=6.82 \times 10^{4} \mathrm{MPa}$ and $v=0.3$ of Poisson's ratio [20]. Stress-strain data for this structures is shown in Table 1. This experimental data was taken by Santosa [21] and Annisa J [20], who was adopted form Langseth and Hopperstad [22].

In this work, numerical study through dynamic simulation software is used as methods of research. Rigid floor and double-tube elements are contacted using automatic node 
surface. The structures were designed using Belytschko-Tsay four node shell elements through the thickness, which was fixed at off axis lower plate. Mesh convergence analyses were carried out with the element sizes of 5X5 mm for shell elements and 10X10 mm for discrete rigid plate. The impact plate is constrained in all directions, except vertical direction of $\mathrm{Z}$ axis which is coincided with the impact path. Furthermore, the velocity of crush is $16 \mathrm{~m} / \mathrm{s}$.

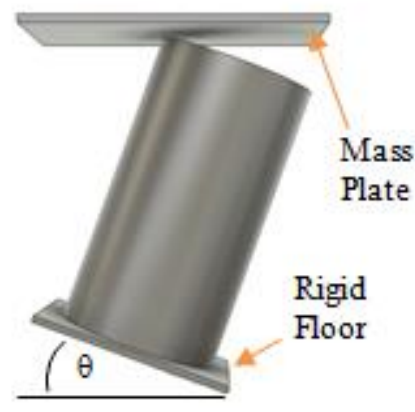

(a)

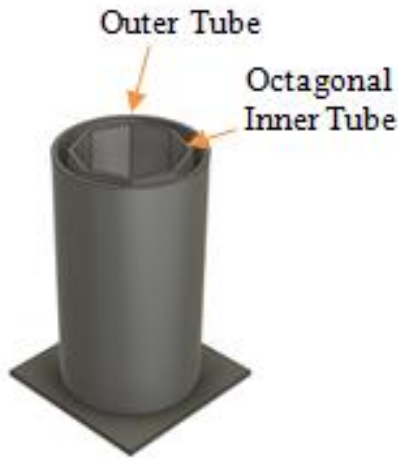

(b)

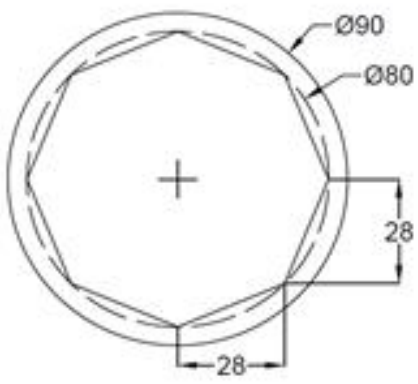

(c)

Fig. 2 (a) off-axis oblique method, (b) design of the structures and (c) size of the structures

Table 1 Stress-strain dat of aluminium alloy 6060 T4 [20]

\begin{tabular}{cc}
\hline Plastic stress $(\mathrm{MPa})$ & Plastic strain $(\%)$ \\
\hline 80 & 0 \\
115 & 2.4 \\
139 & 4.9 \\
150 & 7.4 \\
158 & 9.9 \\
167 & 12.4 \\
171 & 14.9 \\
173 & 17.4 \\
\hline
\end{tabular}

\section{PARAMETERS}

The crashworthiness indicators [23] of thin-walled structures such as specific energy absorption (SEA), maximum force $\left(F_{\max }\right.$ ) and crash force efficiency (CFE) are considered to calculate.

\section{A. Specific energy absorption (SEA)}

SEA is calculated for determining energy absorption capacity of the structures, where SEA is defined from energy absorption (EA) divided by the total mass of structure $(m)$. A suitable structure should have higher value of SEA [23].

$$
S E A=\frac{E A}{m}
$$

Meanwhile, EA is obtained by the absorbed energy form the structure. EA is calculated as the area under forcedisplacement curve. $\delta_{c}$ is the maximum displacement that rigid floor collapses a structure, $\delta$ is the rigid floor displacement and $F(\delta)$ is variation of force versus displacement [23].

$$
E A=\int_{0}^{\delta_{c}} F(\delta) d \delta
$$

\section{B. Maximum force $\left(F_{\max }\right)$}

Maximum force is known as the peak collapse force. The maximum force can be seen in the force-displacement curve. This indicator tends to decrease for sake of vehicle safety. A suitable structure should have less value of maximum force [23].

$F_{\text {max }}=$ maximum (force - displacement curve)

\section{Crash force efficiency (CFE)}

Crash force efficiency (CFE) is another crashworthiness parameter to determine efficiency of crash force in percent. It is calculated by dividing mean force to maximum force. Mean force is the ratio of the total energy absorption from the tubes to the effective stroke length $(\delta$ ). In order to get best value of CFE, it should be equal to $100 \%$ [23].

$$
C F E=\frac{F_{\text {mean }}}{F_{\text {max }}} \times 100
$$

\section{NUMERICAL RESULTS AND DISCUSSION}

Figure 3 presents deformation of crushing octagonal-inner double tubes with various thicknesses of $1 \mathrm{~mm}, 2 \mathrm{~mm}, 3 \mathrm{~mm}$ and $4 \mathrm{~mm}$. All the tubes are analyzed under off-axis oblique load based on the descriptions given in section 2 . It is reminded that upper plate as a rigid wall crushes $72 \%$ of the total length of the tubes where $130 \mathrm{~mm}$ from the total length of $180 \mathrm{~mm}$. From simulation, distance between rigid wall and double tubes is $2 \mathrm{~mm}$ before crushing.

All the structures have been studied by using dynamic crush to know the energy absorption. From figure 3, the structures loaded under axial crush of $0^{\circ}$ shows quite similar deformation although they have different thickness, while the 
folded size during crush looks different due to thickness of structures. When the structures were loaded for oblique crush of $10^{\circ}$, the structures tend to move just that little laterally because they are obliquely crushed. On the other hand, the structures still look like axial loading which still maintains axial position. For oblique impacts of $20^{\circ}$ and $30^{\circ}$, all the structures collapses in less effective global crushing mode because the specimens are following the rigid-wall until ends of deformation.

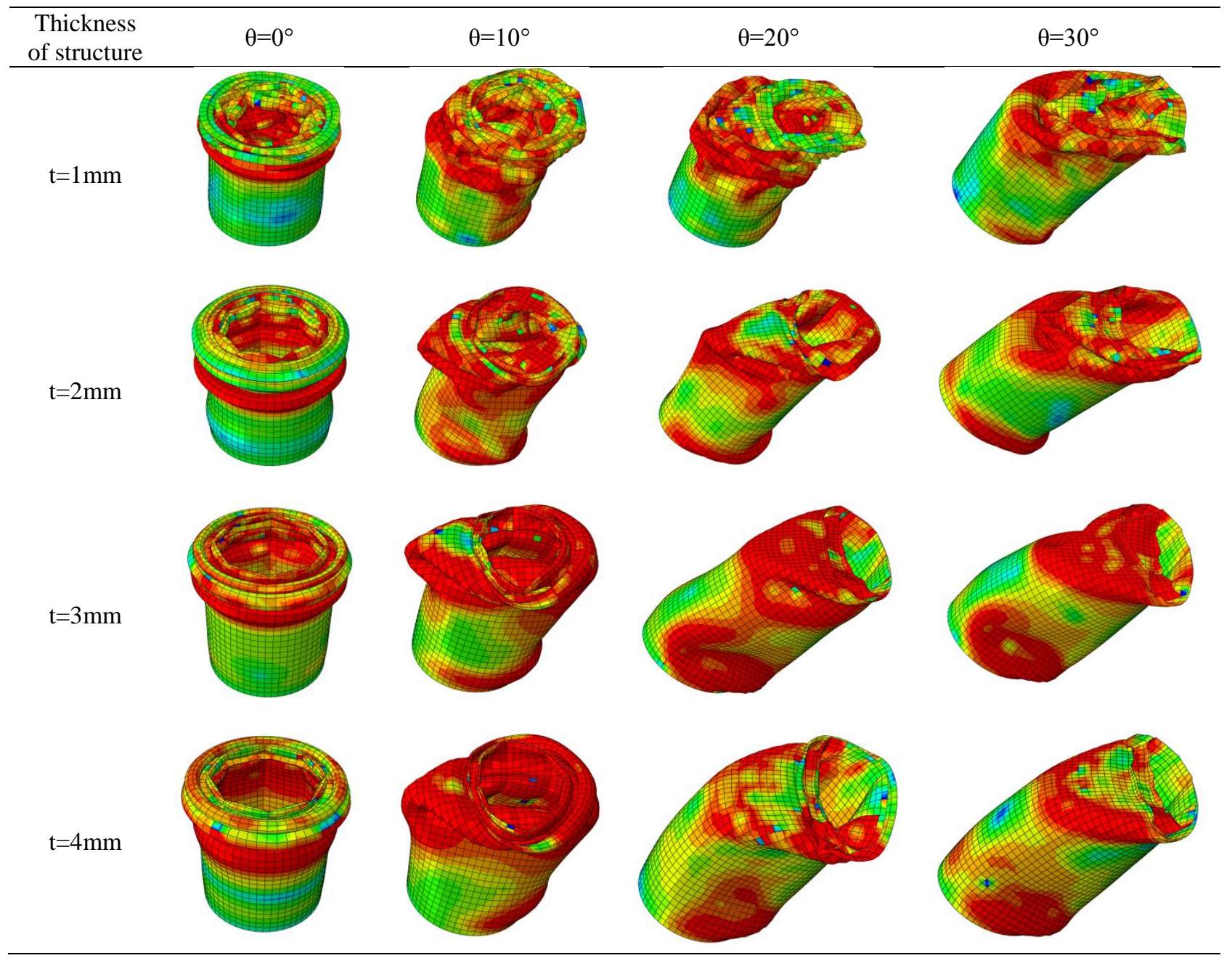

Fig. 3 Deformation of structures analyzed in different thickness under off-axis oblique load

Figure 3 displays the influence of thickness from all the structures under off-axis oblique crushing. It can be shown that the thicker the tubes are, the stronger face of lower area they are. For the case of axial crush of $0^{\circ}$, the structures with thickness of $1 \mathrm{~mm}$ and $2 \mathrm{~mm}$ appear bending in a region of lower surface while the thickness tubes of $3 \mathrm{~mm}$ and $4 \mathrm{~mm}$ seem secure. Furthermore, lower surfaces of all structures simulated obliquely $\left(\theta=10^{\circ}, 20^{\circ}\right.$ and $\left.30^{\circ}\right)$ varies. When the structures are crushed, for all obliquely loaded structures, the faces are folded not only in the beginning of crush but also in the end of bottom position from tubes. In addition, more folds are found in thin walls $(t=1 \mathrm{~mm}$ and $2 \mathrm{~mm})$ than thick walls $(\mathrm{t}=3 \mathrm{~mm}$ and $4 \mathrm{~mm})$.

Figure 4 shows curves of force-displacement taken from numerical simulation analysis for octagonal-inner double tubes. According to figure 4, structures with $4 \mathrm{~mm}$ thickness dominantly reached the highest force among all the structures compared to other wall thickness. It was followed by structures of thickness $3 \mathrm{~mm}, 2 \mathrm{~mm}$ until $1 \mathrm{~mm}$. However, $1 \mathrm{~mm}$ wall thickness shows insignificant force starting from first crush for all types of loads.

For the case of axial impact (figure 4a), the curve displays all unstably loaded structures for all wall-thickness of the tubes. It is noteworthy that the first peak load between $2 \mathrm{~mm}$ and $3 \mathrm{~mm}$ structures shows similarly. On the other hand, oblique impacts of $10^{\circ}, 20^{\circ}$ and $30^{\circ}$ (figure $4 \mathrm{a}, \mathrm{b}$ and $\mathrm{c}$ ) seemed different with axial impact. The obliquely forced structures were seen steadily from initial force to displacement of almost $140 \mathrm{~mm}$. The structures were also found that the first highest load occurred in around the displacement of $40 \mathrm{~mm}$. All tubes loaded obliquely enhanced to get first peak and tended to decrease constantly until last displacement measured. Nevertheless, the structures increased modestly during the crush at the end of displacement.

Based on numerical simulation results, the crashworthiness analysis of octagonal-inner double tubes was compared with different thickness under off axial oblique load. Mass of all tubes presented was varied where it 
depended on thickness of the tubes. The important parameters of crashworthiness such as energy absorption, specific energy absorption, maximum force, mean force and crush force efficiency were calculated from force-displacement curves of the structures displayed in table 2. Under axial loading conditions, the numerical result presented that a $4 \mathrm{~mm}$ thickness wall structure had more energy absorption than other structures of thickness because the number of folds for $4 \mathrm{~mm}$ thickness was more than other tubes occurred during simulation (figure 3). It similarly happened to obliquely loaded tubes that $4 \mathrm{~mm}$-thickness wall tubes had higher energy absorption.
As we can see in order to compare the graph in figure 4, the graph shows that force-displacement of axial load $0^{\circ}$ tended to have maximum force many times. Compared to oblique loading from $10^{\circ}$ to $30^{\circ}$, the force-displacement graphs only have one maximum point of force. This effect is due to the tubes were loaded obliquely. However, for the tube with thickness $1 \mathrm{~mm}$, the force of the tube represented constant line. It means that the tube absorbing energy might be safer than other tubes because the structure had good deformation.

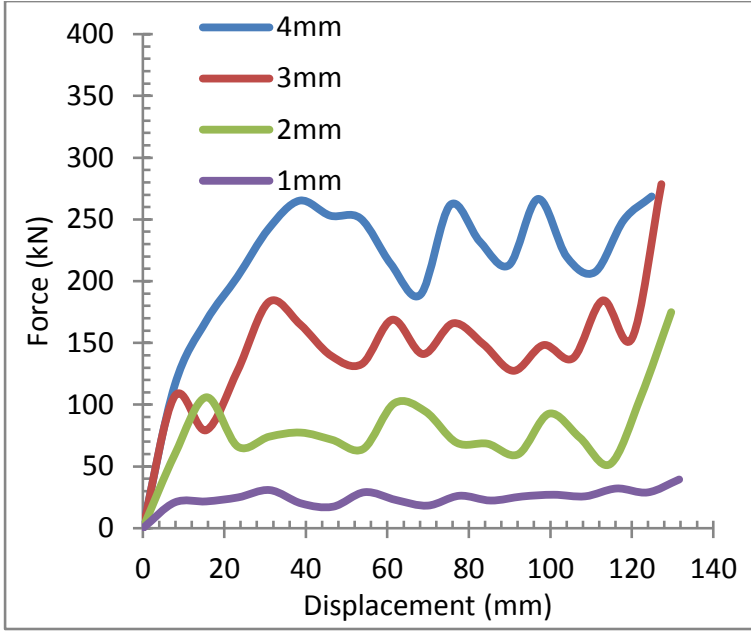

(a)

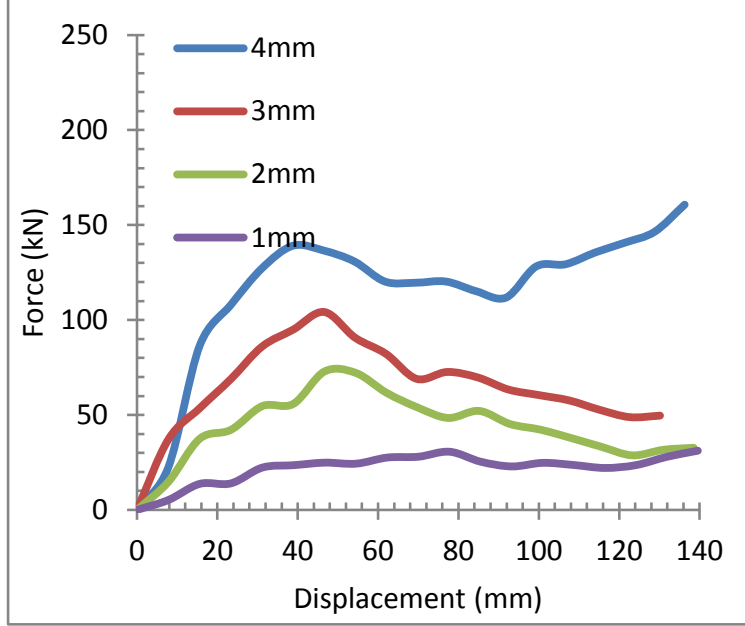

(c)

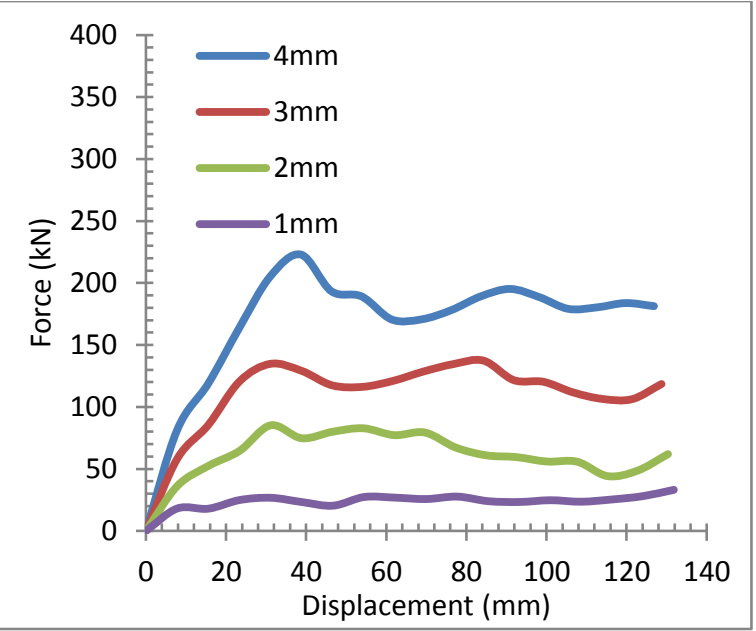

(b)

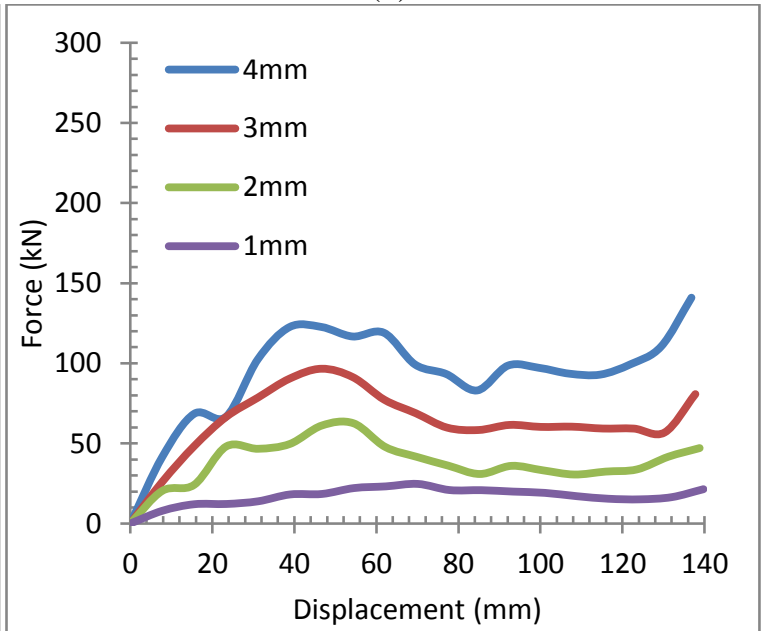

(d)

Fig. 4 Force-displacement curves for octagonal-inner double tubes with different thickness in off-axial oblique angles (a) $\theta=0^{\circ}$, (b) $\theta=10^{\circ}$, (c) $\theta=20^{\circ}$ and (d) $\theta=30^{\circ}$

The percentage of crush force efficiency (CFE) was shown on table 2. From the calculation of crashworthiness indicators, the percentage ratio of CFE was $45 \%$ to $81 \%$. This ratio was influenced by the total average of force divided with maximum force when loading.

Since the structures were crushed under oblique load, the energy absorption (SEA) became decreased for all the size of thickness structures. As matter of fact, from figure 5, the value of specific energy absorption for tubes loaded under $20^{\circ}$ and $30^{\circ}$ obliquely was almost similar with all thickness of the structures. Only load of $0^{\circ}$ and $10^{\circ}$ showed far different value of SEA. Furthermore, a structure with thickness of $1 \mathrm{~mm}$ inscribed little differences of SEA value compared to other walls. The differences of loads were also reduced average force (Fmean) of the structures. It seemed like SEA that thicker structures increased mean force. Nonetheless, tubes between degree of 20 and 30 for oblique simulation inscribed quite similar value of mean force. Furthermore, there was a distinct difference of mean force among varieties of thickness showed in figure 7. 
Table 2 Results of energy absorption of the structures

\begin{tabular}{|c|c|c|c|c|c|c|c|}
\hline \multirow{2}{*}{$\begin{array}{c}\text { Thickness of } \\
\text { structures }\end{array}$} & \multirow{2}{*}{$\begin{array}{l}\text { Oblique } \\
\text { angle }\end{array}$} & \multicolumn{6}{|c|}{ Crashworthiness Parameter } \\
\hline & & Mass (kg) & EA $(J)$ & $\begin{array}{c}\mathrm{SEA} \\
(\mathrm{kJ} / \mathrm{kg})\end{array}$ & Fmax $(k N)$ & Fmean $(\mathrm{kN})$ & CFE (\%) \\
\hline \multirow{4}{*}{$1 \mathrm{~mm}$} & $0^{\circ}$ & 0.256 & 3193.49 & 12.49 & 39.43 & 24.26 & 61.52 \\
\hline & $10^{\circ}$ & 0.256 & 3119.44 & 12.20 & 33.13 & 23.67 & 71.44 \\
\hline & $20^{\circ}$ & 0.256 & 2938.61 & 11.49 & 30.63 & 22.28 & 72.75 \\
\hline & $30^{\circ}$ & 0.256 & 2249.75 & 8.80 & 24.72 & 17.04 & 68.91 \\
\hline \multirow{4}{*}{$2 \mathrm{~mm}$} & $0^{\circ}$ & 0.511 & 10270.36 & 20.08 & 174.91 & 79.20 & 45.28 \\
\hline & $10^{\circ}$ & 0.511 & 8048.04 & 15.74 & 85.19 & 61.75 & 72.48 \\
\hline & $20^{\circ}$ & 0.511 & 5928.74 & 11.59 & 72.89 & 45.27 & 62.12 \\
\hline & $30^{\circ}$ & 0.511 & 5064.01 & 9.90 & 62.58 & 38.60 & 61.68 \\
\hline \multirow{4}{*}{$3 \mathrm{~mm}$} & $0^{\circ}$ & 0.767 & 18426.14 & 24.03 & 204.41 & 144.79 & 51.98 \\
\hline & $10^{\circ}$ & 0.767 & 14408.31 & 18.79 & 137.34 & 111.93 & 81.50 \\
\hline & $20^{\circ}$ & 0.767 & 8604.13 & 11.22 & 94.92 & 68.90 & 72.58 \\
\hline & $30^{\circ}$ & 0.767 & 8371.91 & 10.92 & 96.61 & 64.25 & 66.51 \\
\hline \multirow{4}{*}{$4 \mathrm{~mm}$} & $0^{\circ}$ & 1.022 & 26973.89 & 26.39 & 268.59 & 215.99 & 80.41 \\
\hline & $10^{\circ}$ & 1.022 & 21579.31 & 21.11 & 222.93 & 170.13 & 76.32 \\
\hline & $20^{\circ}$ & 1.022 & 14150.35 & 13.84 & 140.76 & 109.44 & 77.75 \\
\hline & $30^{\circ}$ & 1.022 & 12038.34 & 11.78 & 122.70 & 93.01 & 75.80 \\
\hline
\end{tabular}

Figure 6 displays peak force of all structures. The lower average value of maximum force was the structure with thickness of $1 \mathrm{~mm}$. Structures of $1 \mathrm{~mm}$-thickness had insignificant difference for all loads but still axial load of $0^{\circ}$ was bigger maximum force. However, axial crush for thickness of $2 \mathrm{~mm}, 3 \mathrm{~mm}$ and $4 \mathrm{~mm}$ inscribed farther value of peak force considered to oblique crush. Meanwhile, $20^{\circ}$ oblique crush had quite identical value of maximum force with oblique load of $30^{\circ}$ for all varieties of thickness.

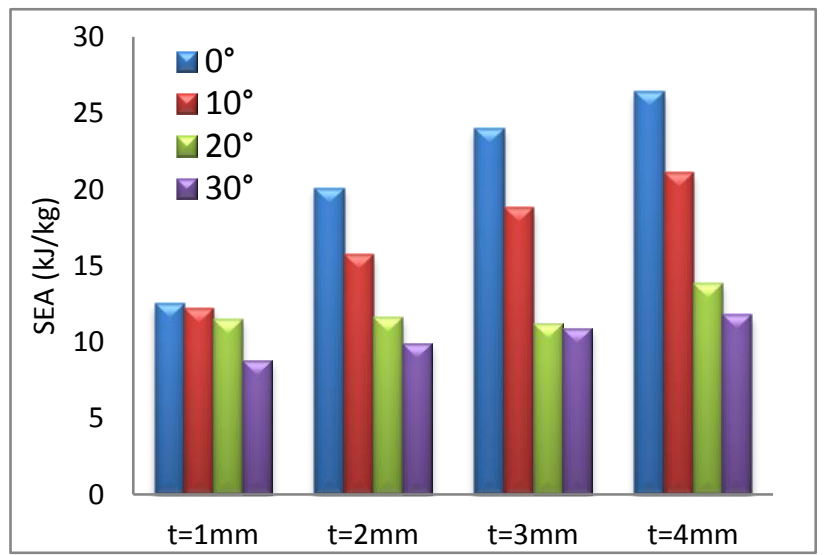

Fig. 5 Crashworthiness parameters of specific energy absorption

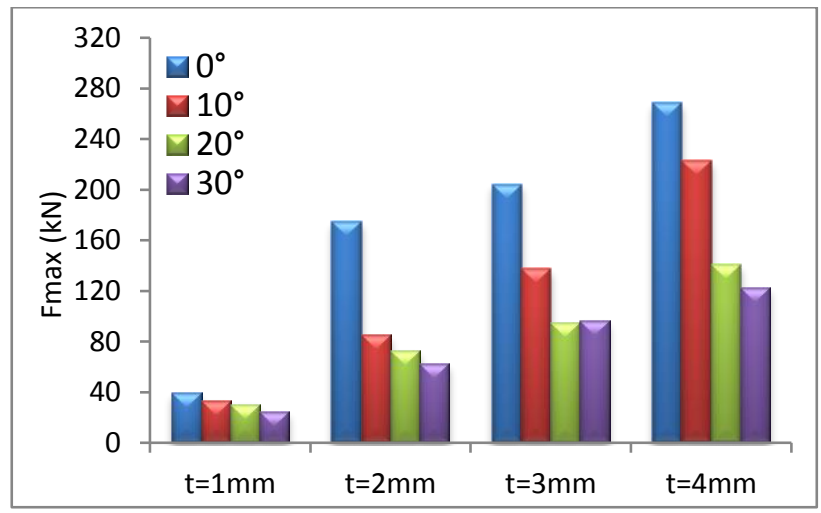

Fig. 6 Crashworthiness parameters of peak force

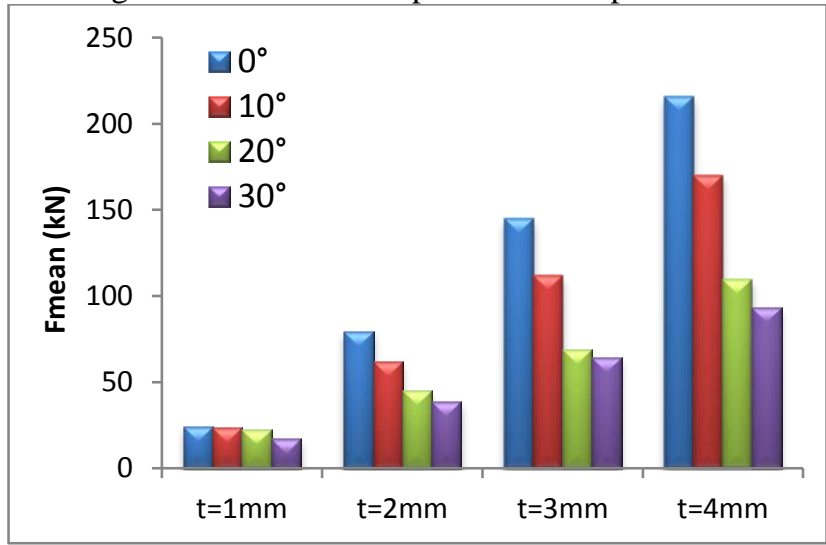

Fig. 7 Crashworthiness parameters of mean collapse load 


\section{V.CONCLUSION}

In this study, the analysis of crashworthiness of octagonalinner double tubes was researched with different thickness under off-axis oblique load. Based on numerical simulation, the crashworthiness indicators have been taken out into calculation to compare the tubes. Several important notes can be concluded from this study. Structures with $4 \mathrm{~mm}$ thickness dominantly reached the highest force among all the structures compared to other wall thickness. However, Tubes with $1 \mathrm{~mm}$ thickness had good deformation. Due to off-axis oblique load, specific energy absorption decreased for all the size of thickness structures. However, the value of specific energy absorption for tubes loaded obliquely $20^{\circ}$ and $30^{\circ}$ was almost similar with all thickness of the structures while load of $0^{\circ}$ and $10^{\circ}$ showed far different value of specifically absorbed energy. This research is going to be continued to experimental study and optimization for further findings.

\section{ACKNOWLEDGMENT}

The authors have not received any grants and funding.

\section{References}

[1] M. D. Goel, "Numerical investigation of the axial impact loading behaviour of single, double and stiffened circular tubes," vol. 8265, no. November, hal. $0-10,2015$.

[2] X. Zhang, H. Zhang, C. Yang, dan K. Leng, "Static and dynamic axial crushing of self-locking multi-cell tubes," Int. J. Impact Eng., vol. 127, no. August 2018, hal. 17-30, 2019.

[3] F. Djamaluddin, S. Abdullah, A. K. Ariffin, dan Z. M. Nopiah, "Optimisation and validation of full and half foam filled double circular tube under multiple load cases," Int. J. Crashworthiness, vol. 24, no. 4, hal. 389-398, 2019.

[4] F. Djamaluddin, S. Abdullah, A. K. Ariffin, dan Z. M. Nopiah, "Finite element analysis and crashworthiness optimization of foam-filled double circular under oblique loading," Lat. Am. J. Solids Struct., vol. 13, no. 11, hal. 2176-2189, 2016.

[5] I. V. Kannan dan R. Rajkumar, "Deformation and energy absorption analysis of simple and multi-cell thin-walled tubes under quasi-static axial crushing," Int. J. Crashworthiness, vol. 0, no. 0, hal. 1-10, 2019.

[6] A. Jusuf, T. Dirgantara, L. Gunawan, dan I. S. Putra, "Crashworthiness analysis of multi-cell prismatic structures," Int. J. Impact Eng., vol. 78, hal. 34-50, 2015.

[7] A. A. Dastjerdi, H. Shahsavari, A. Eyvazian, dan F. Tarlochan, "Crushing analysis and multi-objective optimization of different length bi-thin walled cylindrical structures under axial impact loading," Eng. Optim., vol. 0, no. 0, hal. 1-18, 2019.

[8] F. Djamaluddin, S. Abdullah, A. K. Arrifin, dan Z. M. Nopiah, "Crush analysis of the foam-filled bitubal circular tube under oblique impact," IOP Conf. Ser. Mater. Sci. Eng., vol. 308, no. 1, 2018.

[9] X. Zhang dan H. Zhang, "Axial crushing of circular multi-cell columns," Int. J. Impact Eng., vol. 65, hal. 110-125, 2014.

[10] G. Sun, F. Xu, G. Li, dan Q. Li, "Crashing analysis and multiobjective optimization for thin-walled structures with functionally graded thickness," Int. J. Impact Eng., vol. 64, hal. 62-74, 2014.

[11] P. Kaczyński, Z. Gronostajski, dan S. Polak, "Progressive crushing as a new mechanism of energy absorption. The crushing study of magnesium alloy crash-boxes," Int. J. Impact Eng., vol. 124, hal. 1-8, 2019.

[12] R. A. Eshkoor et al., "Failure mechanism of woven natural silk/epoxy rectangular composite tubes under axial quasi-static crushing test using trigger mechanism," Int. J. Impact Eng., vol. 64, hal. 53-61, 2014.

[13] M. Anghileri, L. M. L. Castelletti, E. Francesconi, A. Milanese, dan M. Pittofrati, "Survey of numerical approaches to analyse the behavior of a composite skin panel during a water impact," Int. J. Impact Eng., vol. 63, hal. 43-51, 2014.

[14] H. S. Kim dan T. Wierzbicki, "Numerical and analytical study on deep biaxial bending collapse of thin-walled beams," Int. J. Mech. Sci., vol. 42, no. 10, hal. 1947-1970, 2000.

[15] H. S. Kim dan T. Wierzbicki, "Crush behavior of thinwalled prismatic columns under combined bending and compression," Comput. Struct., vol. 79, no. 15, hal. 1417-1432, 2001.

[16] J. Song, "Numerical simulation on windowed tubes subjected to oblique impact loading and a new method for the design of obliquely loaded tubes," Int. J. Impact Eng., vol. 54, hal. 192-205, 2013.

[17] O. Mohammadiha, H. Beheshti, dan F. H. Aboutalebi, "Multi-objective optimisation of functionally graded honeycomb filled crash boxes under oblique impact loading," Int. J. Crashworthiness, vol. 20, no. 1, hal. 44-59, 2015.

[18] X. Deng, "Crushing analysis and multi-objective crashworthiness optimization of multi-cell conical tube subjected to oblique loading," vol. 11, no. 381, hal. 1-20, 2019.

[19] N. Tanlak, "shape optimization of thin-walled tubes under high-velocity axial and transverse impact loadings," no. September 2014, 2019.

[20] A. Jusuf, F. S. Allam, T. Dirgantara, L. Gunawan, dan I. S. Putra, "Low velocity impact analyses of prismatic columns using finite element method," Key Eng. Mater., vol. 462-463, hal. 1308-1313, 2011.

[21] S. P. Santosa, "Crashworthiness analysis of ultralight metal structures," Massachusetts Institute of Technology, 1999.

[22] M. Langseth dan O. S. Hopperstad, "Static and dynamic axial crushing of square thin-walled aluminium extrusions," Int. J. Impact Eng., vol. 18, no. 7-8, hal. 949-968, 1996.

[23] S. Pirmohammad dan S. A. Saravani, "Crashworthiness Performance of Stiffened Foamfilled Tapered Structures under Axial and Oblique Dynamic Loads," vol. 15, no. 1988, 2018.

Creative Commons Attribution License 4.0 (Attribution 4.0 International, CC BY 4.0)

This article is published under the terms of the Creative Commons Attribution License 4.0 https://creativecommons.org/licenses/by/4.0/deed.en US 